Gut, 1982, 23, 1055-1059

\title{
Changes in gastric secretion with time after vagotomy and the relationship to recurrent duodenal ulcer*
}

\author{
D J BUTTERFIELD, P F WHITFIELD, and M HOBSLEY $\dagger$ \\ From the Department of Surgical Studies, The Middlesex Hospital, London
}

SUMMARY We studied 29 patients who had gastric secretion tests after a vagotomy for duodenal ulcer. There were 14 patients who developed a recurrent duodenal ulcer during the follow-up period and 15 patients who remained free from recurrence. Insulin-stimulated gastric secretion increased with time in the recurrent ulcer group, but not in the group with a satisfactory outcome. On the basis of our results, post-vagotomy patients could be divided into three groups. The first group had a high secretion immediately after the operation and it remained high. The risk of recurrent ulcer in that group was about $50 \%$. The second group had an initially low secretion which increased with time, and the risk of recurrent ulcer in that group was the same as for the first group. The third group had an early low secretion which did not increase with time and the risk of recurrence in this group was less than $5 \%$.

Vagotomy shares with other effective treatments for duodenal ulcer the property of reducing the secretion of acid and pepsin by the stomach. When peptic ulceration recurs after vagotomy, it is possible that the cause is inadequate reduction of gastric secretion. Previous publications from this department $^{12}$ have demonstrated that a low measurement of insulin-stimulated gastric secretion at varying times after a vagotomy correlates well with the absence of recurrent ulceration at the time of the secretory test.

Another of our publications ${ }^{3}$ demonstrated stability of insulin-stimulated gastric secretion after vagotomy, although in a group of patients mostly without recurrent ulcer. Watkins and Duthie, ${ }^{4}$ however, found that peak acid output and the difference between peak acid output and basal acid output increased with time in patients who developed recurrent ulcer after vagotomy. This rise was not seen in patients who remained free from recurrence.

The present paper examines our now increased data on the stability of insulin-stimulated gastric secretion after vagotomy in patients with and without recurrent ulcer to determine whether a

\footnotetext{
* Based on a paper read to the meeting of the British Society of Gastroenterology, April 1981.

+ Address for correspondence: Professor M Hobsley, Department of Surgical Studies, The Middlesex Hospital, Mortimer Street, London W1N 8AA.

Accepted for publication 1 March 1982
}

gastric secretion test, done in the early postvagotomy period, can predict recurrence.

\section{Methods}

\section{DESIGN OF STUDY}

We studied the records of 29 patients who had had at least two postoperative secretion tests after vagotomy, one within six months of the operation and the other at least six months later. Two patients had had a truncal vagotomy, 10 a selective vagotomy, and 17 a proximal gastric vagotomy. Fourteen of the 29 patients had developed a symptomatic recurrent duodenal ulcer, which was proven by endoscopy. The median time after operation for the diagnosis of the recurrence was 29 months (range 12-55 months). The other 15 patients either had no clinical indication for an endoscopy, or underwent a negative endoscopy. The median follow-up time for these patients was 27 months (range 10-77 months).

The mean ages at the time of operation were $45 \cdot 7$ years for the non-recurrent group and 47.5 years for the recurrent ulcer group. Two of the 15 nonrecurrent patients were female compared with five of the 14 in the recurrent ulcer group.

Gastric secretion tests began with a basal collection for at least 30 minutes. Hypoglycaemia was then evoked by an intravenous bolus dose of soluble insulin 0.2 units $/ \mathrm{kg}$. and its adequacy was checked by measuring blood glucose concentration 
on venous samples taken at 15,30 , and 45 minutes after the injection of insulin. The volume of gastric juice collected in 10-minute periods for half to two hours after the insulin injection was measured, corrected for pyloric loss and duodenogastric reflux, and standardised for height (standardised gastric secretion). This is the index we have called $\frac{1}{2}-2 V_{G}$ in earlier papers. From our previous work, ${ }^{2}$ the threshold value of standardised gastric secretion, which discriminated between a high and low incidence of recurrent ulceration, was $73 \mathrm{ml} / \mathrm{h}$. Above this threshold there was a $50 \%$ incidence, and, below, a 3\% incidence of recurrent ulcer. The secretory tests and calculations have been described. ${ }^{5}$

The reproducibility of the gastric secretion tests was tested in nine patients who had two preoperative secretion tests.

\section{Results}

\section{REPRODUंCIBILITY OF STANDARDISED GASTRIC SECRETION MEASUREMENT}

In the nine patients who had two preoperative tests, a hierarchical analysis of variance was carried out and this showed that to be $95 \%$ confident that there was a difference between two measurements of standardised gastric secretion on the same patient under the same conditions, the difference had to be at least $24 \mathrm{ml} / \mathrm{h}$ (Table).

\section{ALTERATION OF STANDARDISED GASTRIC SECRETION WITH TIME}

The median times after operation of the early tests were two months for both the non-recurrent and recurrent ulcer groups. The median times after operation of the late tests were 20 months for the non-recurrent group (range 10 to 67 months) and 29.5 months for the recurrent ulcer group (range seven to 60 months).

The median values for standardised gastric secretion for the early tests were $61.6 \mathrm{ml} / \mathrm{h}$ for the non-recurrent group (range 6.4 to $232.9 \mathrm{ml} / \mathrm{h}$ ), and $43.7 \mathrm{ml} / \mathrm{h}$ for the recurrent ulcer group (range 17.9 to $226.8 \mathrm{ml} / \mathrm{h}$ ) (Fig. 1). There was no significant difference between these values using a Wilcoxon test for unpaired data.

The median value of standardised gastric secretion in the late test in the non-recurrent group was $86.0 \mathrm{ml} / \mathrm{h}$ (range 32.3 to $209.9 \mathrm{ml} / \mathrm{h}$ ), which is not a significant increase over the same measurenient at the early test (Wilcoxon test for paired data) (Fig. 1).

The median value of standardised gastric secretion at the late test in the recurrent ulcer group was $121.0 \mathrm{ml} / \mathrm{h}$ (range 55.3 to $266.2 \mathrm{ml} / \mathrm{h}$ ), which is

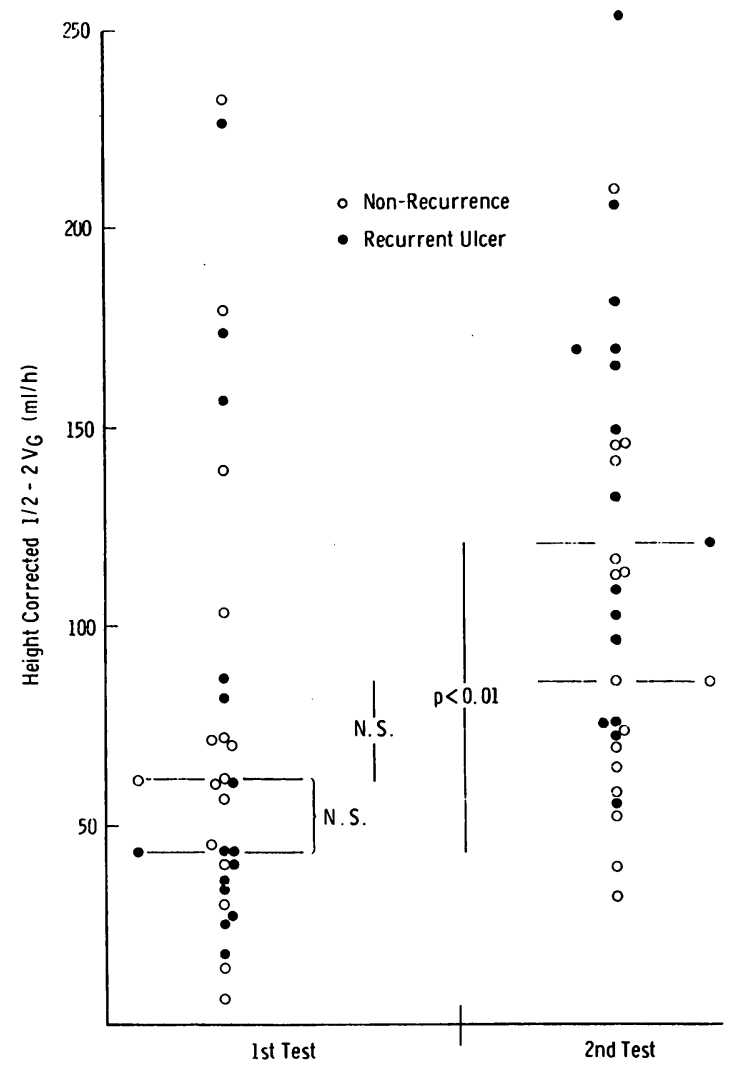

Fig. 1 Individual values for height corrected $\frac{1}{2}-2 V_{G}$ for each of the tests in the study. The median value for each group is shown.

significantly higher than at the time of the early test $(\mathrm{p}<0.01$, Wilcoxon test for paired data) (Fig. 1).

\section{ULCER STATUS AT TIME OF TESTING}

None of the 14 patients in the recurrent ulcer group had the recurrence diagnosed at the time of the first test. At the time of the second test only four of the 14 patients in the recurrent ulcer group did not have an already proven recurrent duodenal ulcer. Proof of recurrence was obtained one, two, two, and 48 months after the test in those four patients.

\section{PREDICTING RECURRENCE BY EARLY}

MEASUREMENT OF STANDARDISED GASTRIC

SECRETION

Of the 29 early tests, $20(69 \%)$ values of standardised gastric secretion fell in the low risk category - that is, below $73 \mathrm{ml} / \mathrm{h}$. Nine $(45 \%)$ of these 20 low measurements were in patients in the recurrent ulcer group. Nine $(31 \%)$ patients had standardised gastric secretion measured at above 73 


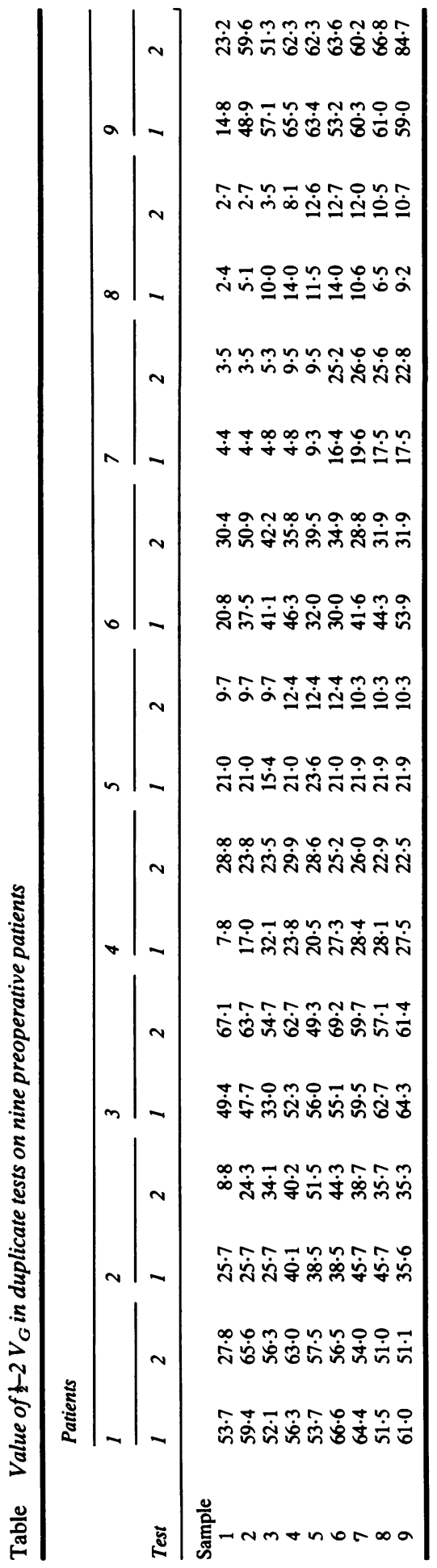


$\mathrm{ml} / \mathrm{h}$ at the early test. Five $(50 \%)$ of the nine patients went on to develop a recurrent ulcer (Fig. 2). Therefore, when a secretion test is performed within the first six months of operation the risk of developing a recurrent duodenal ulcer is not significantly different whether the standardised gastric secretion is above or below $73 \mathrm{ml} / \mathrm{h}\left(\chi^{2}=0.016\right.$, $0.9<\mathrm{p}<0.95)$.

\section{RECURRENT ULCER AND LATE MEASUREMENT OF} STANDARDISED GASTRIC SECRETION

By the time of the late test only eight $(28 \%)$ values of standardised gastric secretion fell below $73 \mathrm{ml} / \mathrm{h}$. Two of those eight patients were in the recurrent ulcer group. One of the two patients had a standardised gastric secretion of $72 \cdot 2 \mathrm{ml} / \mathrm{h}$. The other had the second test seven months after vagotomy but did not develop the recurrence for a further 48 months.

Twenty-one $(72 \%)$ of the 29 patients had a standardised gastric secretion in the second test above $73 \mathrm{ml} / \mathrm{h}$ and $57 \%$ of them (12) were in the recurrent ulcer group (Fig. 2).

\section{Discussion}

What is the relationship between post-vagotomy secretion and recurrent peptic ulceration? Maybury et al found an excellent correlation between a value of standardised gastric secretion below $73 \mathrm{ml} / \mathrm{h}$ and the absence of a recurrent ulcer at the time of the test. ${ }^{2}$ Of the patients with a standardised gastric secretion above $73 \mathrm{ml} / \mathrm{h}$, half had a recurrent ulcer, while of patients with a standardised gastric

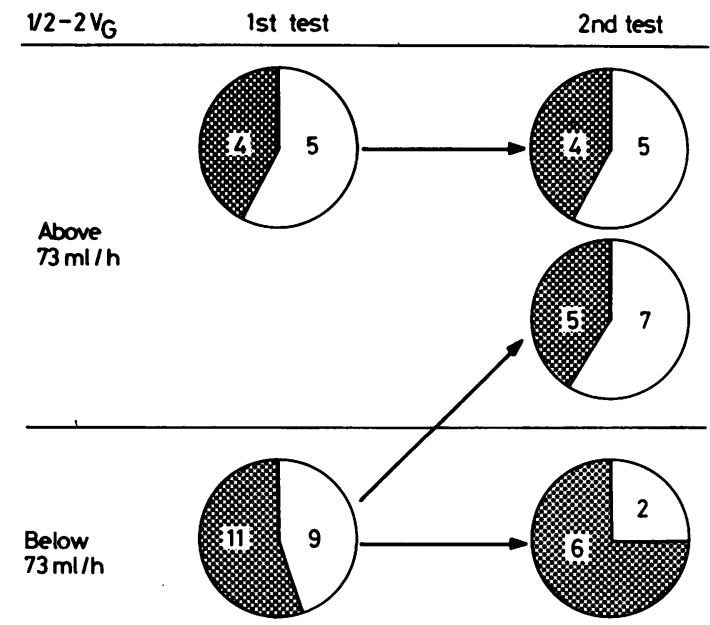

Fig. 2 Relationship of the $\frac{1}{2}-2 V_{G}$ to the development of a recurrent ulcer. Stippled area $=$ non-recurrence. secretion less than $73 \mathrm{ml} / \mathrm{h}$ less than $5 \%$ had a recurrent ulcer.

It is important to note that the reproducibility study in this paper would indicate that the value 73 $\mathrm{ml} / \mathrm{h}$ must be thought of only as the centre of a range of values between 49 and $97 \mathrm{ml} / \mathrm{h}$, and not as a sharp cut-off point.

The results of our study confirm the findings of Maybury et al. From the viewpoint of patients with recurrent ulcer, 13 of the 28 tests on our 14 recurrent ulcer patients were carried out either after the recurrent ulcer had been diagnosed or within the two months preceding endoscopic diagnosis. (The fourteenth patient did not have a recurrence diagnosed until 48 months after his second test). In only one of the 13 tests was the standardised gastric secretion below $73 \mathrm{ml} / \mathrm{h}$. The actual value was $72 \cdot 2$ $\mathrm{ml} / \mathrm{h}$ which, as our reproducibility study shows, is not significantly different from $73 \mathrm{ml} / \mathrm{h}$. From the other viewpoint of acid secretion, of all the 58 secretion test results reported in this study, 30 had standardised gastric secretion values greater than 73 $\mathrm{ml} / \mathrm{h}$, and $12(40 \%)$ of these were in patients with a proven recurrent ulcer or an ulcer which was to be demonstrated within two months of the test. In other words, if the secretion in any test is greater than $73 \mathrm{ml} / \mathrm{h}$ there is a $40 \%$ chance of a recurrent ulcer being present. In 28 tests the standardised gastric secretion was less than $73 \mathrm{ml} / \mathrm{h}$ and only one $(4 \%)$ of these had a diagnosed recurrent ulcer.

When performed within the first six months of vagotomy, gastric secretion tests measuring standardised gastric secretion are not able to discriminate between patients who will develop a recurrent ulcer and those who will remain recurrence-free. Even in the group where standardised gastric secretion was below $73 \mathrm{ml} / \mathrm{h}$, the incidence of later recurrent ulceration approached $50 \%$ (nine out of 20, Fig. 2). The probable reason for this high incidence is that there is a higher percentage of patients with recurrent ulcer in the study as a whole than in a normal post-vagotomy population. This is due to patients with recurrent ulcer being more likely to have a second late secretion test than asymptomatic patients, even though our policy has been to try to repeat secretion tests several months after operation.

Previous work from this department has shown that there is an excellent correlation between a negative intraoperative Burge test and a standardised gastric secretion less than $73 \mathrm{ml} / \mathrm{h}$ in the early postoperative period. ${ }^{6}$ Because we have shown in this paper that an early low standardised gastric secretion cannot prognosticate recurrence of ulceration, we must infer that a negative Burge test 
is unable to exclude the future development of a recurrent duodenal ulcer. Indeed, two of our recurrent ulcer patients were Burge negative at the time of their vagotomy.

The reason for this is that there is a group of patients whose gastric secretion rises with time after vagotomy, thus shifting them from our low risk category to our high risk category. The risk of recurrent ulceration developing in this group is at least as great if not greater than the risk if the secretion had been high from the start of the postoperative period.

Two of our recurrent ulcer patients had standardised gastric secretion below $73 \mathrm{ml} / \mathrm{h}$ at the time of the second test. The value of one of these was $72 \cdot 2 \mathrm{ml} / \mathrm{h}$ and, as explained by our reproducibility study, could be included in our high risk group. The other value was $55.3 \mathrm{ml} / \mathrm{h}$, but this value was obtained from a secretion test performed seven months after operation and 48 months before the diagnosis of recurrence and is therefore possibly not a reliable measurement of his final postoperative secretion.

Thus, instead of the grouping as given previously, the true situation may well be that in 14 patients gastric secretion increased from below to above the $73 \mathrm{ml} / \mathrm{h}$ threshold with nine developing a recurrence, and that none of the six patients whose secretion started and remained below $73 \mathrm{ml} / \mathrm{h}$ developed a recurrent ulcer (Fig. 3). This emphasised the importance of a rise in secretion after an apparently

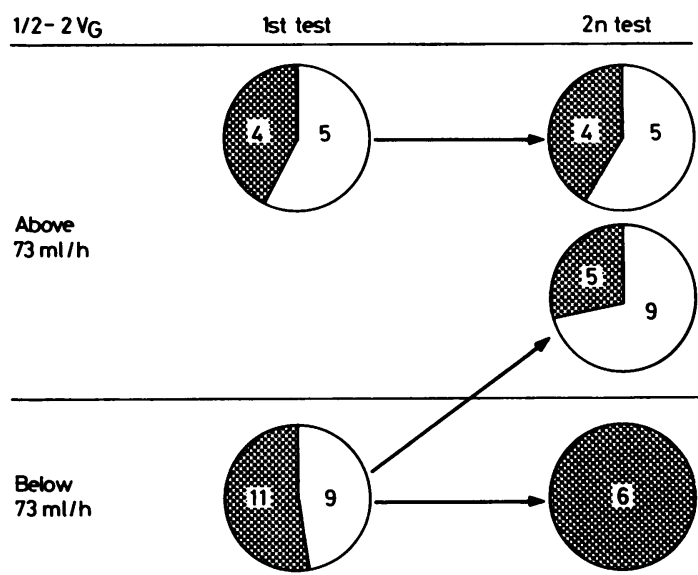

Fig. 3 Relationship of the $\frac{1}{2}-2 V_{G}$ to the development of a recurrent ulcer after altering the grouping of two patients. Stippled area $=$ non-recurrence. adequate vagotomy as a factor in the development of a recurrent ulcer. It would appear that secretion studies after vagotomy define three groups of patients, one with a high secretion rate that remains high (high risk of recurrence); one with a low secretion that remains low (low risk of recurrence); and one with a low secretion shortly after operation that later rises and puts the patient into the high risk category.

The mechanism for this rise in secretion is not known. Postulates include post-vagotomy hypergastrinaemia due to hyperplasia of $G$ cells in response to alkaline conditions in the antrum, increased sensitivity to gastrin of gastric parietal cells after denervation, or recovery of vagal function.

\section{Conclusion}

There is an incidence of recurrent ulcer after vagotomy even when an early insulin test has indicated a complete vagotomy. Recurrent ulcer in this group occurs only in patients whose insulin stimulated secretion rises with time. The mechanism of this rise in secretion is not known.

\section{References}

1 Faber RG, Russell RCG, Parkin JV, Whitfield P, Hobsley $M$. The predictive accuracy of the postvagotomy insulin test: a new interpretation. Gut 1975; 16: $337-42$.

2 Maybury NK, Faber RG, Hobsley M. Post-vagotomy insulin test: improved predictability of ulcer recurrence after correction for height and collection errors. Gut 1977; 18: 449-56.

3 Faber RG, Parkin JV, Whitfield P, Hobsley M. Stability of insulin-induced gastric secretion after vagotomy. Gut 1975; 16: 343-6.

4 Watkins DFL, Duthie HL. Changes in the postoperative insulin test in relation to recurrent duodenal ulcer. Gut 1971; 12: 303-10.

5 Whitfield PF, Hobsley M. A standardised technique for the performance of accurate gastric secretion studies. Agents and Actions 1979; 19/4: 327-32.

6 Maybury NK, Russell RCG, Faber RG, Hobsley M. A new interpretation of the insulin test, validated and then compared with the Burge test. Br J Surg 1977; 64: 673-6. 